\title{
Quantitative Structure-Property Relationship Studies on Ostwald Solubility and Partition Coefficients of Organic Solutes in Ionic Liquids
}

\author{
Alan R. Katritzky, ${ }^{*}$, Minati Kuanar,${ }^{\S}$ Iva B. Stoyanova-Slavova, ${ }^{\S}$ Svetoslav H. Slavov, ${ }^{\S}$ Dimitar A. Dobchev,, ,॥ \\ Mati Karelson," and William E. Acree, Jr. ${ }^{\perp}$
}

Center for Heterocyclic Compounds, Department of Chemistry, University of Florida, Gainesville, Florida 32611, Department of Chemistry, Tallinn University of Technology, Akadeemia tee 15, Tallinn 12618, Estonia, and Department of Chemistry, University of North Texas, Denton, Texas 76203-5070

\begin{abstract}
Interactions of solutes with diverse ionic liquid solvents have been investigated by quantitative structureproperty relationship (QSPR) methodology. Ostwald solubility coefficients and partition coefficients of organic solutes in eight different ionic liquids are correlated by molecular descriptors calculated solely from their structures. Two- to four-parameter best multilinear regression models were obtained with coefficients of determination ranging from 0.913 to 0.992 . Additionally, several models were obtained with the same descriptors for all eight ionic liquids (ILs). Charge-related type descriptors contributed significantly to most of the models. The QSPR models were validated using the leave-one-out cross validation method.
\end{abstract}

\section{Introduction}

Ionic liquids (ILs) are a class of novel compounds that are composed entirely of ions, contain at least one organic ion in an ion pair, and are liquid at or near room temperature. ILs have received a great deal of attention due to their unique properties such as solvation ability for a wide range of compounds, high thermal stability, electroconductivity, and very low vapor pressure. ${ }^{1}$ Ionic liquids have found potential applications in "green" chemistries, separation processes, and various catalytic reactions. ${ }^{2-4}$

Experimental solubilities and infinite dilution activity coefficients, $\gamma_{i}^{\infty}$, of solutes dissolved in ionic liquids are important properties, which describe solute-solvent interactions. These properties have practical applications in commercial processes involving chromatographic separations and liquid-liquid extractions. Several publications report limited experimental measurements of the infinite dilution activity coefficients, ${ }^{5-12} \gamma_{i}^{\infty}$, and Henry's law constants ${ }^{13,14}$ of various solutes in different ILs. However, the literature lacks data for the solubility of many common organic chemicals in ionic liquids. Hence, a quantitative structure-property relationship (QSPR) theoretical approach that would provide quantitative correlation and hence the possibility of prediction of solubilities in ionic liquids, together with additional physical properties, could benefit researchers in this area.

Quantitative structure-property relationship studies have found wide applications in various research areas of chemistry, as an efficient tool in the correlation and prediction of diverse physicochemical properties. Several physicochemical and biological properties such as aqueous solubilities, vapor pressures, water-air partition coefficients, ${ }^{15,16}$ partitioning behavior of organic solutes in aqueous biphasic systems, ${ }^{17}$ blood-air and tissue-air partition coefficients of organic solutes, ${ }^{18,19}$ partition

* Corresponding author. Phone: (352) 392-0554. Fax: (352) 392-9199.

E-mail: katritzky@chem.ufl.edu.

${ }^{\S}$ University of Florida.

" Tallinn University of Technology.

${ }^{\perp}$ University of North Texas. of drugs between human milk and plasma, ${ }^{20}$ and blood-to-brain distribution coefficients of drugs ${ }^{21}$ were investigated by our group.

In recent years, QSPR methodology has been employed for the correlation and prediction of various physicochemical properties of ionic liquids. Melting points of several imidazolium and pyridinium based ionic liquids were correlated by our group using molecular descriptors calculated by the CODESSA Pro program. ${ }^{22,23}$ Previous QSPR models for the correlation of melting points of ionic liquids and related properties ${ }^{24-28}$ included studies by Abraham and co-workers ${ }^{29-31}$ based on linear free energy relationship (LFER) methods for the prediction of partition coefficients of various solutes in ionic liquids.

Gutowski et al. ${ }^{32}$ have correlated the enthalpies of formation and stabilities of energetic ionic liquids by ab initio electronic structure calculations. Semiempirical methods including UNIFAC group contributions and COSMO-RS were applied to predict infinite dilution activity coefficients of ionic liquids. ${ }^{33,34}$ Eike et al. ${ }^{35}$ correlated infinite dilution activity coefficients for 38 solutes in three ionic liquids (1-butyl-4-methylpyridinium tetrafluoroborate, 1-methyl-3-ethylimidazolium bis(trifluoromethylsulfonyl)imide, and 1,2-dimethyl-3-ethylimidazolium bis(trifluoromethylsulfonyl)imide) with a correlation coefficients of 0.90 to 0.99 by QSPR methodology. Tamm and Burk ${ }^{36}$ correlated the infinite dilution activity coefficients of three ionic liquids for the same set of 38 organic compounds with structural descriptors. QSPR models for the toxicity data of ionic liquids $\left(\log \mathrm{IC}_{50}\right.$ and $\log \mathrm{LC}_{50}$ ) were reported with an $R^{2}$ of 0.78 to $0.88 .^{37}$

Our group reported a general treatment of solubility in traditional organic solvents. ${ }^{38-40}$ In continuation of this earlier work, we have now attempted the correlation of the solubility of solutes in various ionic liquids. The present study develops QSPR models for the correlation of Ostwald solubility coefficients $(\log L)$ and partition coefficients $(\log P)$ of organic solutes in eight ionic liquids based on molecular descriptors calculated solely from the structure of a molecule. 


\section{Data Set}

The experimental data for the present work based on the infinite dilution activity coefficients of solutes in eight different ionic liquids, such as 1-methyl-3-ethylimidazolium bis(trifluoromethylsulfonyl)imide ([meim $]^{+}\left[\mathrm{Tf}_{2} \mathrm{~N}\right]^{-}$) IL-I, 1,2-dimethyl-3-ethylimidazolium bis(trifluoromethylsulfonyl)imide $\left(\left[\mathrm{m}_{2} \mathrm{eim}\right]^{+}\left[\mathrm{Tf}_{2} \mathrm{~N}\right]^{-}\right) \mathrm{IL}-$ II, 1-methyl-3-butylimidazolium bis(trifluoromethylsulfonyl)imide $\left([\mathrm{mbim}]^{+}\left[\mathrm{Tf}_{2} \mathrm{~N}\right]^{-}\right)$IL-III, 1-methyl-3-hexylimidazolium bis(trifluoromethylsulfonyl)imide $\left([\mathrm{mhim}]^{+}\left[\mathrm{Tf}_{2} \mathrm{~N}\right]^{-}\right) \mathrm{IL}-\mathrm{IV}$, trimethylbutylammonium bis(trifluoromethylsulfonyl)imide $\left(\left[\mathrm{m}_{3} \text { bam }\right]^{+}-\right.$ $\left.\left[\mathrm{Tf}_{2} \mathrm{~N}\right]^{-}\right)$IL-V, 1-methyl-3-octylimidazolium tetrafluoroborate $\left([\mathrm{moim}]^{+}\left[\mathrm{BF}_{4}\right]^{-}\right)$IL-VI, 1-methyl-3-butylimidazolium hexafluorophosphate $\left([\mathrm{mbim}]^{+}\left[\mathrm{PF}_{6}\right]^{-}\right)$IL-VII, and 4-methyl- $N$-butylpyridinium tetrafluoroborate $\left([\mathrm{mbpy}]^{+}\left[\mathrm{BF}_{4}\right]^{-}\right) \mathrm{IL}-\mathrm{VIII}$, were collected from 20 literature sources. ${ }^{5,6,8,10,12-14,34,41-52}$ Except for IL-VIII, which contains a pyridinium ring, all the ILs investigated are imidazoliums. For ionic liquids I to V, the anion is bis(trifluoromethylsulfonyl)imide $\left[\mathrm{Tf}_{2} \mathrm{~N}\right]^{-}$. For ILs VI and VIII, it is tetrafluoroborate $\left[\mathrm{BF}_{4}\right]^{-}$, while IL-VII contains the hexafluorophosphate $\left[\mathrm{PF}_{6}\right]^{-}$counterion. Each data set contains 30 to 60 organic solutes.

For each of the eight ILs, the Ostwald solubility coefficients $(\log L)$ were computed by eq 1 for all 92 organic solutes with available data. In eq $1, \gamma_{i}^{\infty}$ is the infinite dilution activity coefficient; $p$ is the vapor pressure of the solute at the system temperature; and $V$ is the molar volume of the ionic liquid solvent.

$$
\begin{aligned}
\log L & =\log \left(R T / \gamma_{\mathrm{i}}^{\infty} p V\right) \\
\log P & =\log L-\log L_{\mathrm{W}}
\end{aligned}
$$

The partition coefficients $\log P$ for the solutes in the eight ionic liquids were calculated by eq 2 , where $L_{\mathrm{W}}$ is the Ostwald coefficient of the solute in water. The Ostwald solubility coefficients $(\log L)$ and partition coefficients $(\log P)$ were calculated by eqs 1 and 2 .

\section{Methodology}

QSPR Modeling. The 2D-structures of the compounds were drawn using ChemDraw. ${ }^{53} \mathrm{~A}$ three-dimensional conversion and preoptimization were performed using the molecular mechanics (MM+) implemented in the HyperChem 7.01 package. ${ }^{54}$ Final geometry optimization of the molecules was carried out by using the semiempirical quantum-mechanical AM1 parametrization. A gradient norm $0.042 \mathrm{~kJ} \cdot \AA^{-1}$ was applied in the geometry optimization for all structures as a stopping criterion. The optimized geometries were then loaded into CODESSA Pro software. ${ }^{55}$ The CODESSA Pro program was used to calculate up to 725 different molecular descriptors, derived from the molecular structure for each solute and classified as: (i) constitutional, (ii) geometrical, (iii) topological, (iv) chargerelated, (v) quantum chemical, and (vi) thermodynamic.

The best multilinear regression (BMLR) procedure available in the framework of the CODESSA-Pro was used to find the best correlation models from selected noncollinear descriptors. After defining the descriptor space for the solutes, the BMLR procedure ${ }^{56}$ was used to find the best correlation between the descriptors and property. The BMLR selects the best two-parameter regression equations, then the best threeparameter regression equations, etc., on the basis of the highest $R^{2}$ and $F$ values in a stepwise regression procedure. The result obtained by BMLR is the "best" representation of the property in the given descriptors pool. To develop QSPR models, it is important to decide when to stop the addition of descriptors during the stepwise regression pro- cedure. An excessive number of descriptors could lead to overparameterized equations that are difficult to interpret in terms of interactions and mechanisms. Based on the variation of $R^{2}, R_{\text {cv }}^{2}$, and $F$ values with respect to the number of descriptors in the equation, the optimum regression model was selected with the optimum low number of descriptors.

\section{Results and Discussion}

QSPR Modeling of Ostwald Solubility Coefficient $(\log L)$. The best three or four descriptor multilinear regression equations were developed for $\log L$ in eight ionic liquids. The statistical characteristics for each of these models are shown in Table 1. The BMLR method produced the best models in the respective descriptor spaces. To avoid the incorporation of collinear descriptors, a threshold value of $R^{2}$ intercorr. $\leq 0.5$ between the descriptors was set. Altogether, 16 different descriptors were involved in the QSPR models for the eight ILs I to VIII. The descriptor types include charge related $\left(\mathrm{d}_{3}, \mathrm{~d}_{4}, \mathrm{~d}_{6}, \mathrm{~d}_{7}, \mathrm{~d}_{8}, \mathrm{~d}_{22}, \mathrm{~d}_{26}\right.$, and $\left.\mathrm{d}_{27}\right)$, geometrical $\left(\mathrm{d}_{5}\right.$, $\left.\mathrm{d}_{24}\right)$, topological $\left(\mathrm{d}_{14}, \mathrm{~d}_{25}\right)$, and quantum mechanical $\left(\mathrm{d}_{17}, \mathrm{~d}_{18}\right.$, $\mathrm{d}_{19}$, and $\mathrm{d}_{28}$ ). Their occurrence in the BMLR models is listed in Table 2. The coefficients of determination $R^{2}$ for the models reported ranged from 0.919 to 0.992 , and variances $s^{2}$ ranged from 0.012 to 0.069 (Table 1 ). These parameters indicate satisfactory quality of the regressions.

The most important descriptors involved in the $\log L$ models depict the charge distribution within the molecules, which is a main factor describing the electrostatic interactions between the solute and the IL (see Table 2). In general, $\log L$ increases with increasing hydrogen donor/acceptor ability of the solute. The above conjectures are supported by the occurrences of the descriptors as given in Table 2, coupled with the positive contributions of the hydrogen bonding descriptors in the eqs in Table 1 .

The descriptors Information content parameter, Randic index, and Gravitational index significantly contribute toward the solubility of organic solutes in ILs. They should account for the size and shape effects of the molecules in intermolecular interactions. The quantum mechanical descriptors $\mathrm{d}_{17}$ to $\mathrm{d}_{19}$ and $\mathrm{d}_{28}$ reflect the interatomic interactions averaged by the number of the atoms for a given molecule. The predicted values of log $L$ for ILs I to IV are listed in Table 3, and the plot of the predicted versus observed plots for ILs I to IV is shown in Figure 1a to $d$ (the remaining results for ILs V to VIII are given in Supporting Information SM1).

QSPR Modeling of Partition Coefficients $(\log P)$. A second goal of this investigation was to develop robust QSPR based on the BMLR method for partition coefficients $(\log P)$ defined by eq 2 . The best two-parameter models found for the eight ILs are shown in Table 4a. Seven different descriptors $\left(d_{2}\right.$, $\mathrm{d}_{11}, \mathrm{~d}_{12}, \mathrm{~d}_{13}, \mathrm{~d}_{15}, \mathrm{~d}_{16}$, and $\mathrm{d}_{20}$ ) were involved in the QSPR models for $\log P$ in the ILs-I to VIII. The descriptors DPSA2 difference in CPSAs (PPSA2-PNSA2) Zefirov PC $d_{2}$, and Minimum partial charge (Zefirov) for all atom types $d_{12}$ are common to most of the equations. Table $4 \mathrm{a}$ demonstrates excellent correlations, with coefficients of determination $R^{2}$ from 0.913 to 0.987 . The most significant parameter in these models is Minimum partial charge (Zefirov) for all atom types $\left(d_{12}\right)$, which reflects the interaction of solutes and solvents (ILs). The cross-validated correlation coefficients $R_{\text {CV }}^{2}$ (Table 4a) range from 0.896 to 0.986 , suggesting good predictability for the equations. The leave-one-out algorithm was used for this validation. All descriptors involved in the QSPR models for $\log P$ are listed in Table $4 \mathrm{~b}$. 
Table 1. Statistical Parameters for BMLR Models of Ostwald Solubility Coefficient $(\log L)^{a}$

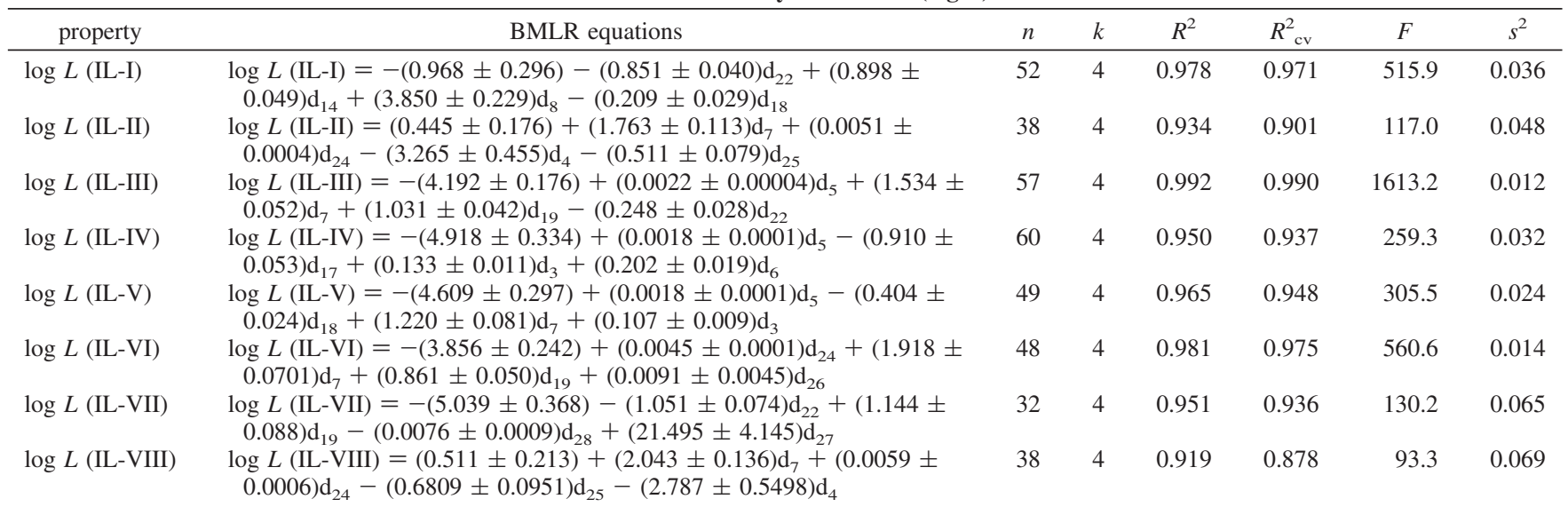

${ }^{a} \mathrm{NB}$ : number of data points $(n)$, number of descriptors $(k)$, squared correlation coefficient $\left(R^{2}\right)$, cross validated squared correlation coefficient $\left(R_{\mathrm{cv}}^{2}\right)$, Fisher ratio $(F)$, squared standard deviation $\left(s^{2}\right)$.

Table 2. Descriptors Involved in the QSPR Models for $\log L$ in Eight ILs, I to VIII

\begin{tabular}{|c|c|c|c|c|c|c|c|c|c|}
\hline descriptors & symbols & $\begin{array}{c}\log \\
L \text { IL-I }\end{array}$ & $\begin{array}{c}\log \\
L \text { IL-II }\end{array}$ & $\begin{array}{c}\log \\
L \text { IL-III }\end{array}$ & $\underset{L \text { IL-IV }}{\log }$ & $\begin{array}{l}\log \\
L \text { IL-V }\end{array}$ & $\log _{L \mathrm{IL}-\mathrm{VI}}$ & $\begin{array}{c}\log \\
L \mathrm{IL}-\mathrm{VII}\end{array}$ & $\underset{L \text { IL-VIII }}{\log }$ \\
\hline average complementary information content (order 0 ) & $d_{25}$ & & $x$ & & & & & & $x$ \\
\hline count of H-donor sites (Zefirov PC) all & $d_{26}$ & & & & & & $x$ & & \\
\hline DPSA3 difference in CPSAs (PPSA3-PNSA3) (Zefirov PC) & $d_{3}$ & & & & $x$ & $x$ & & & \\
\hline FNSA-2 fractional PNSA (PNSA-2/TMSA) (MOPAC PC) & $\mathrm{d}_{4}$ & & $x$ & & & & & & $x$ \\
\hline gravitation index (all atom pairs) & $d_{5}$ & & & $x$ & $x$ & $x$ & & & \\
\hline gravitation index (all bonds) & $\mathrm{d}_{24}$ & & $x$ & & & & $x$ & & $x$ \\
\hline HA dependent HDCA-1 (MOPAC PC) & $d_{6}$ & & & & $\times$ & & & & \\
\hline HA dependent HDCA-2 (MOPAC PC) & $\mathrm{d}_{7}$ & & $x$ & $x$ & & $x$ & $x$ & & $\times$ \\
\hline HA dependent HDSA-2/SQRT(TMSA) (Zefirov PC) & $\mathrm{d}_{8}$ & $x$ & & & & & & & \\
\hline HASA-2/TMSA (Zefirov PC) & $d_{27}$ & & & & & & & $x$ & \\
\hline Randic index (order 3) & $\mathrm{d}_{14}$ & $x$ & & & & & & & \\
\hline total molecular 2-center exchange energy/\# of atoms & $d_{17}$ & & & & $\times$ & & & & \\
\hline total molecular 2-center resonance energy & $d_{28}$ & & & & & & & $x$ & \\
\hline total molecular 2-center resonance energy/\# of atoms & $\mathrm{d}_{18}$ & $x$ & & & & $\times$ & & & \\
\hline total molecular electrostatic interaction/\# of atoms & $\mathrm{d}_{19}$ & & & $x$ & & & $\times$ & $x$ & \\
\hline WNSA3 weighted PNSA (PNSA3*TMSA/1000) (Zefirov PC) & $d_{22}$ & $x$ & & $x$ & & & & $x$ & \\
\hline
\end{tabular}

Also, the predicted values of $\log P$ and the predicted vs observed plots for $\log P$ in ILs I to VIII are included in Supporting Information SM2.

Cross Validation. To validate the BMLR models developed for $\log L$ and $\log P$, the parent data points were divided according to the experimental values into three subsets (A, B, C) as follows: the first, fourth, seventh, etc. data points comprise the first subset (A), the second, fifth, eighth, etc. comprise the second subset (B), and the third, sixth, ninth, etc. comprise the third subset $(C)$. Three training sets were prepared as combinations of two subsets (A and B), (A and $\mathrm{C}$ ), and (B and $\mathrm{C}$ ). For each training set, the correlation equation was derived with the descriptors of the respective equations given in Tables 1 and $4 \mathrm{a}$. The equations obtained were then used to predict $\log L$ and $\log P$ values for the compounds from the remaining test set (A, B, or $\mathrm{C})$. The efficiency of QSPR models to predict $\log L$ and $\log P$ values was assessed by the squared correlation coefficients and standard deviations between experimental and predicted data for each test set (A, B, or C). The stability of the models is indicated by the close agreement of the average values of (i) $R^{2}$ (Fit) and $R^{2}$ (Pred) and (ii) the standard errors $s^{2}$ (Fit) and $s^{2}$ (Pred). For example, the $R^{2}$ (Fit) values for $\log L$ ILs I to VIII range from 0.926 to 0.992 , and $R^{2}$ (Pred) values range from 0.908 to 0.990 , respectively. The results from this validation are shown in Supporting Information SM3. These statistical parameters suggest good predictive power for each equation in $\log L$ and $\log P$.
Common Descriptor Models for $\log$ L. One of the main goals of this work was also to generalize the QSPR representation of $\log L$ for all eight ILs. More precisely, we aimed to build a model with the same descriptors common for all eight ILs. To do this, we explored the occurrences of the descriptors in Table 2. The descriptors which appeared in the previous models were preselected. Thus, a smaller descriptor space was formed on which the BMLR was run for each IL. The best four-descriptor regression models for $\log L$ are reported in the Supporting Information (SM-4a): the four descriptors best describing the eight ILs as a group were: DPSA3 difference in CPSAs (PPSA3-PNSA3) (Zefirov $P C) d_{3}$, Gravitation index (all atom pairs), $d_{5}, H A$ dependent HDCA-2 (MOPAC PC) $d_{7}$, Total molecular electrostatic interaction/number of atoms, $d_{19}$. The statistical characteristics of the models are also shown in SM-4a. For ILs I to VIII, four descriptors $\left(d_{3}, d_{5}, d_{7}, d_{19}\right)$ contributed to the model with an $R^{2}$ of 0.988 to 0.868 and $R^{2}{ }_{\mathrm{CV}}$ of 0.984 to 0.778 . Two of these descriptors, Area weighted surface charge of hydrogen bonding donor atoms $d_{7}$ and Difference between atomic charge weighted part positive and negative surface areas $\left(d_{3}\right)$, are related to the charge distribution interaction between the solutes and the ionic liquids. Descriptor $d_{19}$, the Total molecular electrostatic interaction per number of atoms also has a significant role in the solute and solvent interactions. The geometrical descriptor $\mathrm{d}_{5}$ reflects the molecular shape and mass distribution in the solute molecule. 
Table 3. Experimental and Predicted Ostwald Solubility Coefficient $(\log L)$ Values Using BMLR Models in Four Different Ionic Liquids (ILs I to IV)

\begin{tabular}{|c|c|c|c|c|c|c|c|c|c|}
\hline S1. no. & compd name & $\begin{array}{l}\text { exptl log } \\
L(\text { IL-I) }\end{array}$ & $\begin{array}{l}\text { pred. log } \\
L(\text { IL-I) }\end{array}$ & $\begin{array}{l}\text { exptl log } \\
L \text { (IL-II) }\end{array}$ & $\begin{array}{l}\text { pred. log } \\
L \text { (IL-II) }\end{array}$ & $\begin{array}{l}\text { exptl log } \\
L(\text { IL-III) }\end{array}$ & $\begin{array}{l}\text { pred. log } \\
L \text { (IL-III) }\end{array}$ & $\begin{array}{l}\text { exptl log } \\
L(\text { IL-IV) }\end{array}$ & $\begin{array}{l}\text { pred. log } \\
L(\text { IL-IV) }\end{array}$ \\
\hline 1 & Hexane & 1.242 & 1.170 & 1.210 & 1.121 & 1.435 & 1.389 & 1.660 & 1.648 \\
\hline 2 & Heptane & 1.572 & 1.526 & 1.557 & 1.571 & 1.785 & 1.790 & 2.041 & 2.046 \\
\hline 3 & Octane & 1.895 & 1.697 & 1.891 & 1.823 & 2.128 & 2.134 & 2.415 & 2.383 \\
\hline 4 & Nonane & 2.201 & 2.038 & 2.206 & 2.267 & 2.470 & 2.528 & 2.751 & 2.782 \\
\hline 5 & Decane & 2.481 & 2.221 & 2.514 & 2.560 & 2.862 & 2.874 & 3.121 & 3.126 \\
\hline 6 & Cyclohexane & 1.676 & 1.748 & 1.624 & 1.389 & 1.845 & 1.869 & 2.002 & 2.025 \\
\hline 7 & 2,2,4-Trimethylpentane & 1.563 & 1.418 & 1.548 & 1.978 & & 2.456 & & 2.601 \\
\hline 8 & Cyclohexene & 2.001 & 2.005 & 1.961 & 1.903 & 2.130 & 2.146 & 2.260 & 2.347 \\
\hline 9 & Styrene & 3.852 & 3.802 & 3.874 & 3.735 & & 3.849 & & 4.016 \\
\hline 10 & Benzene & 2.812 & 2.801 & 2.814 & 2.736 & 2.883 & 3.035 & 2.886 & 3.243 \\
\hline 11 & Toluene & 3.166 & 3.066 & 3.159 & 3.107 & 3.203 & 3.222 & 3.300 & 3.387 \\
\hline 12 & Ethylbenzene & 3.417 & 3.340 & 3.389 & 3.377 & 3.474 & 3.439 & 3.569 & 3.598 \\
\hline 13 & $o$-Xylene & 3.659 & 3.553 & 3.665 & 3.424 & & 3.501 & & 3.607 \\
\hline 14 & $p$-Xylene & 3.486 & 3.359 & 3.474 & 3.382 & & 3.471 & 3.663 & 3.602 \\
\hline 15 & $m$-Xylene & 3.498 & 3.214 & 3.485 & 3.316 & & 3.460 & 3.688 & 3.588 \\
\hline 16 & Isopropylbenzene & 3.560 & 3.602 & 3.512 & 3.772 & & 3.789 & & 3.903 \\
\hline 17 & tert-Butylbenzene & 3.785 & 3.823 & 3.727 & 4.178 & & 4.222 & & 4.273 \\
\hline 18 & Methanol & 2.655 & 2.883 & 2.510 & 2.760 & 2.589 & 2.583 & 2.478 & 2.408 \\
\hline 19 & Ethanol & 2.855 & 2.710 & 2.693 & 2.844 & 2.756 & 2.789 & 2.659 & 2.719 \\
\hline 20 & 1-Propanol & 3.167 & 3.252 & 3.008 & 3.020 & 3.052 & 3.084 & 3.016 & 3.080 \\
\hline 21 & 1-Butanol & 3.507 & 3.600 & 3.352 & 3.385 & 3.507 & 3.494 & 3.498 & 3.576 \\
\hline 22 & 1-Pentanol & 3.766 & 3.948 & 3.604 & 3.600 & 3.910 & 3.823 & 3.841 & 3.909 \\
\hline 23 & 1-Hexanol & 4.152 & 4.276 & 4.406 & 4.007 & 4.306 & 4.234 & 4.268 & 4.348 \\
\hline 24 & 2-Propanol & 2.863 & 2.613 & 2.712 & 2.914 & 2.831 & 2.958 & 2.797 & 2.849 \\
\hline 25 & tert-Butanol & 2.911 & 2.549 & 2.767 & 3.129 & 2.902 & 3.263 & 2.876 & 3.096 \\
\hline 26 & 2-Butanol & 3.164 & 3.298 & 3.020 & 3.021 & 3.150 & 3.183 & 3.136 & 3.012 \\
\hline 27 & 2-Methyl-2-butanol & 3.251 & 3.268 & 3.101 & 3.107 & 3.286 & 3.376 & 3.303 & 3.091 \\
\hline 28 & Cyclohexanol & 4.502 & 4.260 & 4.353 & 3.924 & 4.462 & 4.442 & 4.336 & 4.218 \\
\hline 29 & Acetonitrile & 3.250 & 2.987 & 3.197 & 2.829 & 3.164 & 2.912 & 3.124 & 2.793 \\
\hline 30 & Acetone & 2.902 & 2.998 & 2.804 & 2.897 & 2.873 & 2.666 & 2.848 & 2.726 \\
\hline 31 & Ethyl acetate & 2.950 & 2.746 & 2.830 & 2.937 & & 3.099 & & 3.119 \\
\hline 32 & Dichloromethane & 2.231 & 2.229 & 2.217 & 2.200 & & 1.080 & & 1.839 \\
\hline 33 & Trichloromethane & 2.590 & 2.486 & 2.565 & 2.414 & & 2.208 & 2.643 & 2.294 \\
\hline 34 & Tetrachloromethane & 2.289 & 2.117 & 2.226 & 2.555 & & 3.396 & & 2.515 \\
\hline 35 & 1-Methylcyclohexene & 2.269 & 2.384 & 2.234 & 2.225 & & 2.520 & & 2.690 \\
\hline 36 & $\alpha$-Methylstyrene & 4.086 & 3.948 & 4.143 & 4.157 & & 4.108 & & 4.205 \\
\hline 37 & Methyl tert-butyl ether & 2.073 & 2.000 & 1.958 & 1.890 & & 2.184 & & 2.394 \\
\hline 38 & Methyl tert-amyl ether & 2.393 & 2.481 & 2.269 & 2.127 & & 2.511 & & 2.653 \\
\hline 39 & Anisole & 4.081 & 4.107 & & 4.009 & & 4.274 & & 4.326 \\
\hline 40 & Benzyl alcohol & 5.580 & 5.712 & & 5.835 & & 5.948 & & 5.744 \\
\hline 41 & Ethyl benzoate & 5.021 & 5.531 & & 5.986 & & 5.930 & & 5.730 \\
\hline 42 & Cyclopentane & 1.338 & 1.556 & & 1.145 & 1.517 & 1.464 & 1.678 & 1.674 \\
\hline 43 & 1-Pentene & 1.133 & 1.212 & & 1.395 & 1.300 & 1.272 & 1.432 & 1.582 \\
\hline 44 & 1-Hexene & 1.476 & 1.512 & & 1.754 & 1.652 & 1.630 & 1.826 & 1.932 \\
\hline 45 & 1-Heptene & 1.796 & 1.749 & & 2.049 & 1.996 & 1.974 & 2.191 & 2.266 \\
\hline 46 & 2-Butanone & 3.201 & 3.377 & & 2.971 & & 2.900 & & 2.914 \\
\hline 47 & 2-Pentanone & 3.455 & 3.450 & & 3.239 & & 3.220 & 3.505 & 3.246 \\
\hline 48 & Cyclopentene & 1.552 & 1.856 & & 1.741 & 1.678 & 1.795 & & 2.046 \\
\hline 49 & Ethane & -0.169 & 0.074 & & 0.053 & -0.058 & -0.253 & & 0.005 \\
\hline 50 & Ethene & -0.011 & 0.497 & & 0.646 & 0.084 & 0.221 & & 0.654 \\
\hline 51 & Propane & 0.205 & 0.235 & & 0.338 & 0.292 & 0.233 & & 0.504 \\
\hline 52 & Propene & 0.449 & 0.512 & & 0.880 & 0.581 & 0.591 & & 0.937 \\
\hline 53 & Butane & & 0.701 & & 0.537 & 0.691 & 0.631 & & 0.896 \\
\hline 54 & Pentane & & 0.997 & & 0.916 & 1.090 & 1.038 & 1.232 & 1.299 \\
\hline 55 & Undecane & & 2.541 & & 2.989 & 3.218 & 3.261 & 3.499 & 3.513 \\
\hline 56 & Dodecane & & 2.711 & & 3.290 & 3.573 & 3.604 & 3.874 & 3.854 \\
\hline 57 & Cycloheptane & & 1.978 & & 1.711 & & 2.293 & 2.583 & 2.421 \\
\hline 58 & 1,3-Cyclohexadiene & & 2.297 & & 2.304 & 2.398 & 2.495 & 2.489 & 2.717 \\
\hline 59 & 1-Butene & & 1.003 & & 1.139 & 0.925 & 0.931 & & 1.255 \\
\hline 60 & 1-Octene & & 2.032 & & 2.411 & 2.337 & 2.334 & 2.559 & 2.621 \\
\hline 61 & 1-Nonene & & 2.260 & & 2.729 & 2.680 & 2.681 & 2.887 & 2.954 \\
\hline 62 & 1-Dodecene & & 3.073 & & 3.840 & 3.639 & 3.769 & 3.864 & 4.027 \\
\hline 63 & 1-Hexyne & & 1.732 & & 2.278 & & 1.927 & 2.348 & 2.175 \\
\hline 64 & 1-Heptyne & & 1.942 & & 2.557 & & 2.223 & 2.856 & 2.458 \\
\hline 65 & 1-Octyne & & 2.218 & & 2.947 & & 2.551 & 3.136 & 2.772 \\
\hline 66 & Propylbenzene & & 3.398 & & 3.693 & 3.754 & 3.692 & 3.872 & 3.841 \\
\hline 67 & Butylbenzene & & 3.526 & & 3.935 & 4.099 & 3.948 & 4.242 & 4.075 \\
\hline 68 & Pentylbenzene & & 3.747 & & 4.251 & 4.466 & 4.247 & 4.708 & 4.379 \\
\hline 69 & 1-Heptanol & & 4.581 & & 4.296 & 4.764 & 4.580 & & 4.668 \\
\hline 70 & 2-Methyl-1-propanol & & 3.300 & & 3.261 & 3.324 & 3.387 & 3.319 & 3.318 \\
\hline 71 & Propanal & & 3.472 & & 2.781 & 2.602 & 2.675 & 2.590 & 2.779 \\
\hline 72 & Butanal & & 3.797 & & 2.943 & 2.922 & 2.905 & 2.942 & 3.026 \\
\hline 73 & Pentanal & & 4.207 & & 3.219 & 3.101 & 3.227 & 3.154 & 3.364 \\
\hline 74 & Hexanal & & 4.534 & & 3.522 & 3.651 & 3.577 & 3.716 & 3.701 \\
\hline 75 & Heptanal & & 4.915 & & 3.842 & 4.028 & 3.942 & 4.076 & 4.052 \\
\hline 76 & Octanal & & 5.259 & & 4.177 & 4.350 & 4.317 & 4.452 & 4.396 \\
\hline 77 & Methyl propanoate & & 2.981 & & 2.895 & 2.969 & 3.068 & 2.998 & 3.036 \\
\hline 78 & Methyl butanoate & & 3.292 & & 3.161 & 3.271 & 3.365 & 3.313 & 3.444 \\
\hline
\end{tabular}


Table 3. Continued

\begin{tabular}{|c|c|c|c|c|c|c|c|c|c|}
\hline Sl. no. & compd name & $\begin{array}{c}\text { exptl log } \\
L(\text { IL-I) }\end{array}$ & $\begin{array}{c}\text { pred. log } \\
L(\text { IL-I) }\end{array}$ & $\begin{array}{l}\text { exptl log } \\
L \text { (IL-II) }\end{array}$ & $\begin{array}{l}\text { pred. log } \\
L \text { (IL-II) }\end{array}$ & $\begin{array}{l}\text { exptl log } \\
L \text { (IL-III) }\end{array}$ & $\begin{array}{l}\text { pred. log } \\
L \text { (IL-III) }\end{array}$ & $\begin{array}{l}\text { exptl log } \\
L \text { (IL-IV) }\end{array}$ & $\begin{array}{l}\text { pred. log } \\
L(\text { IL-IV) }\end{array}$ \\
\hline 79 & Methyl pentanoate & & 3.522 & & 3.420 & 3.598 & 3.629 & 3.689 & 3.747 \\
\hline 80 & Methyl hexanoate & & 3.928 & & 3.730 & 3.865 & 3.968 & 3.934 & 4.131 \\
\hline 81 & Diisopropyl ether & & 1.638 & & 2.134 & & 2.430 & 2.147 & 2.567 \\
\hline 82 & Ethyl tert-butyl ether & & 1.498 & & 2.023 & & 2.420 & & 2.522 \\
\hline 83 & Ethyl tert-amyl ether & & 2.324 & & 2.415 & & 2.858 & 2.629 & 2.949 \\
\hline 84 & Tetrahydrofuran & & 2.448 & & 1.816 & & 2.249 & 2.866 & 2.535 \\
\hline 85 & 1,4-Dioxane & & 3.512 & & 2.715 & 3.506 & 3.431 & & 3.692 \\
\hline 86 & Carbon tetrachloride & & 2.117 & & 2.555 & & 3.396 & 2.474 & 2.515 \\
\hline 87 & Methane & & -0.089 & & -0.030 & & -0.881 & & -0.578 \\
\hline 88 & Diethyl ether & & 1.526 & & 1.426 & & 1.650 & & 1.891 \\
\hline 89 & 1-Nitropropane & & 2.623 & & 3.617 & & 3.663 & & 2.887 \\
\hline 90 & Triethylamine & & 2.984 & & 2.695 & & 2.937 & & 2.802 \\
\hline 91 & Pyridine & & 4.485 & & 4.683 & & 4.983 & & 4.674 \\
\hline 92 & Thiophene & & 4.040 & & 3.311 & & 2.455 & & 3.269 \\
\hline
\end{tabular}

${ }^{a} \mathrm{NB}$ : IL-I $[\mathrm{meim}]^{+}\left[\mathrm{Tf}_{2} \mathrm{~N}\right]^{-}$is 1-methyl-3-ethylimidazolium bis(trifluoromethylsulfonyl)imide; IL-II $[\mathrm{mmeim}]^{+}\left[\mathrm{Tf}_{2} \mathrm{~N}\right]^{-}$is 1,2 -dimethyl-3-ethylimidazolium bis(trifluoromethylsulfonyl)imide; IL-III [mbim $]^{+}\left[\mathrm{Tf}_{2} \mathrm{~N}\right]^{-}$is 1-methyl-3-butylimidazolium bis(trifluoromethylsulfonyl)imide, $\mathrm{IL}^{-\mathrm{IV}}\left[\mathrm{mhim}^{+}\left[\mathrm{Tf}_{2} \mathrm{~N}\right]^{-}\right.$is 1-methyl-3hexylimidazolium bis(trifluoromethylsulfonyl)imide.

Table 4a. Statistical Parameters for BMLR Models of Partition Coefficients (log $P$ )

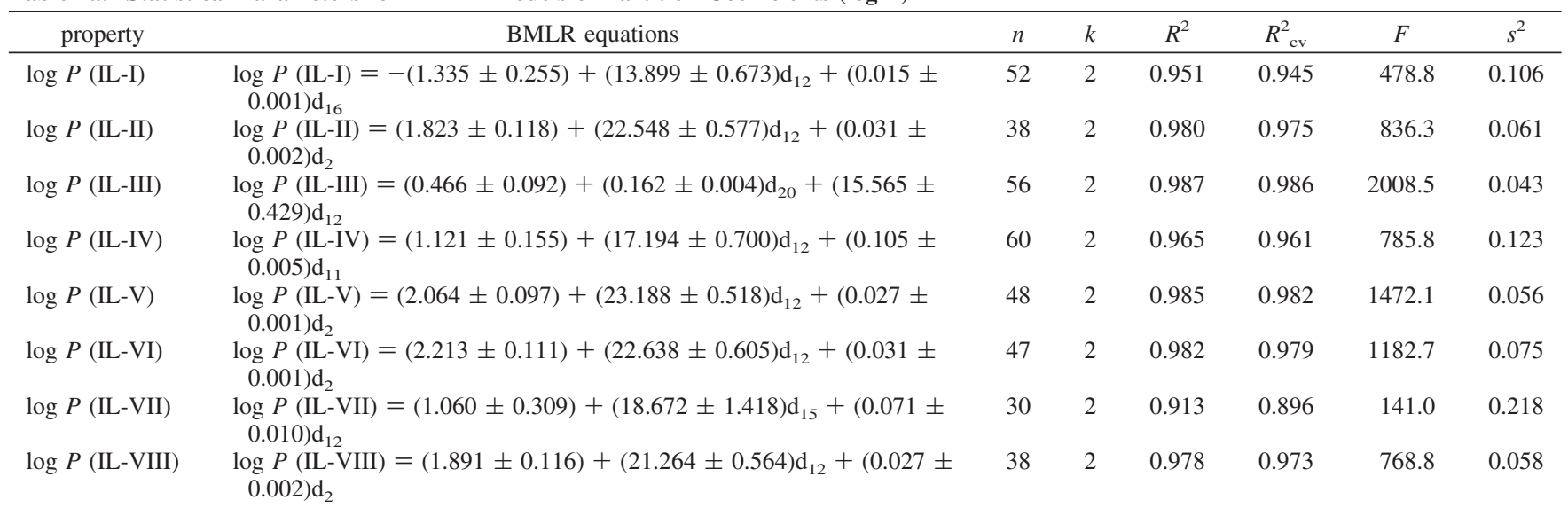

Table 4b. Descriptors Involved in the QSPR Models for $\log P$ in Eight ILs I to VIII

\begin{tabular}{|c|c|c|c|c|c|c|c|c|c|}
\hline descriptors & symbols & $\begin{array}{c}\log P \\
\text { IL-I }\end{array}$ & $\begin{array}{l}\log P \\
\text { IL-II }\end{array}$ & $\begin{array}{l}\log P \\
\text { IL-III }\end{array}$ & $\begin{array}{l}\log P \\
\text { IL-IV }\end{array}$ & $\begin{array}{l}\log P \\
\text { IL-V }\end{array}$ & $\begin{array}{l}\log P \\
\text { IL-VI }\end{array}$ & $\begin{array}{l}\log P \\
\text { IL-VII }\end{array}$ & $\begin{array}{c}\log P \\
\text { IL-VIII }\end{array}$ \\
\hline $\begin{array}{l}\text { DPSA2 difference in CPSAs } \\
\text { (PPSA2-PNSA2) (Zefirov PC) }\end{array}$ & $d_{2}$ & & $x$ & & & $x$ & $x$ & & $x$ \\
\hline $\begin{array}{l}\text { min. partial charge (Zefirov) } \\
\text { for all atom types }\end{array}$ & $d_{12}$ & $x$ & $x$ & $x$ & $x$ & $x$ & $x$ & $x$ & $x$ \\
\hline $\begin{array}{l}\text { PPSA2 total charge weighted } \\
\text { PPSA (Zefirov PC) }\end{array}$ & $d_{13}$ & & & & & & & & \\
\hline total number of atoms & $d_{20}$ & & & $x$ & & & & & \\
\hline
\end{tabular}

Similar general four-descriptor models were reported by Eike et al. ${ }^{35}$ for the prediction of infinite dilution activity coefficients $\left(\ln \gamma_{\mathrm{i}}{ }^{\infty}\right)$ in three ionic liquids, 1-butyl-4-methylpyridinium tetrafluoroborate, 1-methyl-3-ethylimidazolium bis(trifluoromethylsulfonyl)imide, and 1,2-methyl-3-ethylimidazolium bis(trifluoromethylsulfonyl)imide. The authors used calculated octanol-water partition coefficients [log $\left.K_{\text {Ow }}\right]$, hydrogen bond donor counts [Hbonds], surface weighted partial negative surface area $\left[\mathrm{WNSA}_{1}\right]$, and electrotopological state indices $[\mathrm{SaaCH}]$. Similar descriptors were also shown to have significant contributions in our models.

Common Descriptor Models for $\log \boldsymbol{P}$. The same general procedure, as described above for $\log L$, was performed on the $\log P$ data. Overall, just two highly significant descriptors, i.e., DPSA2 difference in CPSAs (PPSA2-PNSA2) Zefirov PC $d_{2}$ and Minimum partial charge (Zefirov) for all atom types $d_{12}$ contribute to all the eight models for $\log P$ (see SM-5a).
Examination of the statistical parameters in SM-5a revealed that the equations for $\log P$ of ILs I to VIII have significant correlations with $R^{2}$ ranging from 0.904 to 0.985 .

\section{External Validation}

The common descriptor models for $\log L$ and $\log P$ were externally validated for their predictive ability. Therefore, we divided the parent set into training and external test sets. Since the number of solutes in some ILs is low, we selected an external set for each IL with five to ten compounds. In the case of $\log L$, the same four descriptors $\left(\mathrm{d}_{3}, \mathrm{~d}_{5}, \mathrm{~d}_{7}\right.$, and $d_{19}$ ) were used to build equations for the training sets (SM$4 a)$ but with different regression coefficients. These equations were used for prediction of the respective test sets for each IL. The statistical characteristics of the validated models for $\log L$ are given in (SM-4b). Plots of predicted vs experimental 

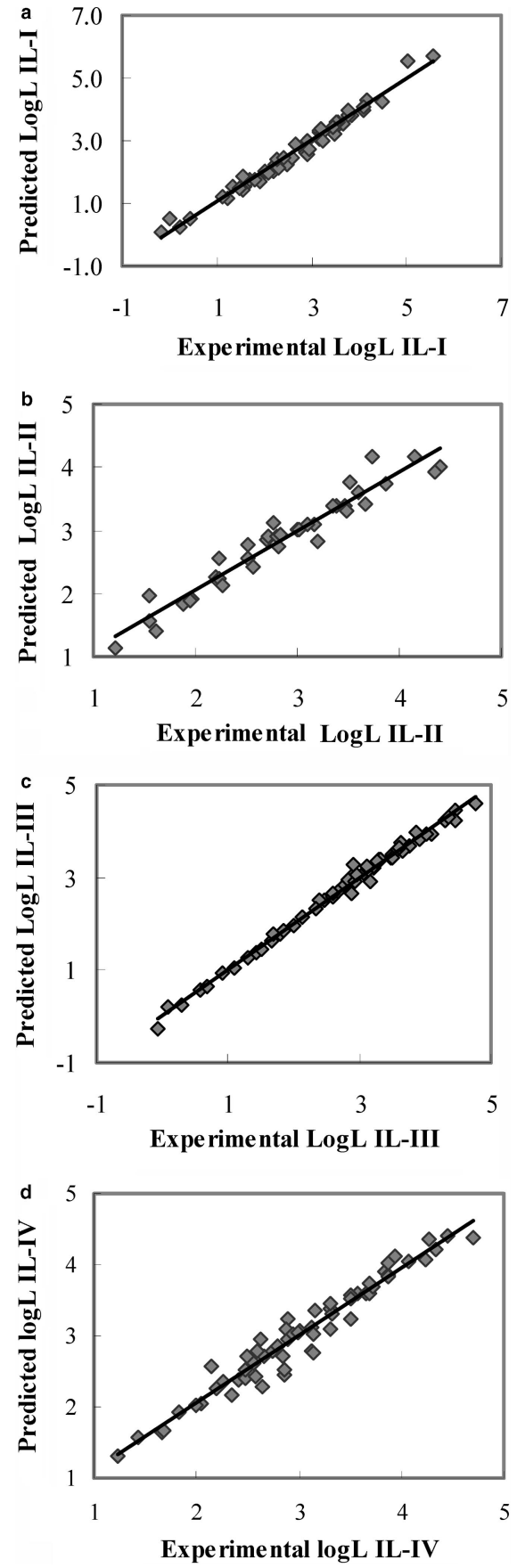

Figure 1. (a) Plot of predicted vs experimental $\log L$ values for IL-I for BMLR models. (b) Plot of predicted vs experimental $\log L$ values for IL-II for BMLR models. (c) Plot of predicted versus experimental $\log L$ values for IL-III for BMLR models. (d) Plot of predicted vs experimental $\log L$ values for IL-IV for BMLR models.

$\log L$ values in the eight ionic liquids (ILs I to VIII) are shown in SM 6, Figures I to VIII, for data points in the training set and for data points left out of the training set (external set). For most of the ILs, the external points were close to the regression line generated by the training set equations. However, in the ILs II and VIII, ethyl acetate deviated slightly from the line.

In the case of $\log P$ validation, the two descriptors $\left(\mathrm{d}_{2}\right.$ and $\mathrm{d}_{12}$ ) were used in the models developed for $\log P$ for all the eight ILs (see SM-5a). For the external test sets, five to ten compounds were selected depending on the number of data points of the parent data sets. Significant QSPR equations were obtained for $\operatorname{LogP}$ in all the eight ILs I to VIII and are shown in (SM-5b).

Plots of the predicted vs experimental $\log P$ values for all eight ILs are given in SM-7. The compounds from the external (validation) data set fit well into the model derived for the training set.

\section{Conclusions}

Valid QSPR models, based on two to four molecular descriptors calculated solely from structure, were obtained for Ostwald solubility $\log L$ and partition coefficient $\log P$. The parameters involved in the correlations reflect the physical significance of specific solute-solvent interactions for various solutes in ionic liquids.

Overall, the QSPR equations developed indicate the significant role in solvent-solute interactions and the chargerelated descriptors alongside as the hydrogen donor/acceptor abilities of the solutes. In addition, the excellent predictive power of the models reported enabled highly accurate estimations of the $\log L$ and $\log P$ values for the external data sets.

The QSPR models developed herein should be useful for prediction of Ostwald solubility coefficients and partition coefficients of unknown solutes in ionic liquids. The common descriptor models developed could be used for the screening for suitable solutes in ionic liquids.

\section{Supporting Information Available:}

SM-1a to SM-7. This material is available free of charge via the Internet at http://pubs.acs.org.

\section{Literature Cited}

(1) Welton, T. Room-Temperature Ionic Liquids. Solvents for Synthesis and Catalysis. Chem. Rev. 1999, 99, 2071-2083.

(2) Sheldon, R. A.; Lau, R. M.; Sorgedrager, M. J.; van Rantwijk, F.; Seddon, K. R. Biocatalysis in Ionic Liquids. Green Chem. 2002, 4, $147-151$.

(3) Dupont, J.; de Souza, R. F.; Suarez, P. A. Z. Ionic Liquid (Molten Salt) Phase Organometallic Catalysis. Chem. Rev. 2002, 102, 36673691.

(4) Seddon, K. R. Ionic Liquids for Clean Technology. J. Chem. Technol. Biotechnol. 1997, 68, 351-356.

(5) Heintz, A.; Kulikov, D. V.; Verevkin, S. P. Thermodynamic Properties of Mixtures Containing Ionic Liquids. Activity Coefficients at Infinite Dilution of Polar Solutes in 4-Methyl-N-butylpyridinium Tetrafluoroborate Using Gas-Liquid Chromatography. J. Chem. Thermodyn. 2002, 34, 1341-1347.

(6) Heintz, A.; Kulikov, D. V.; Verevkin, S. P. Thermodynamic Properties of Mixtures Containing Ionic Liquids. 1. Activity Coefficients at Infinite Dilution of Alkanes, Alkenes, and Alkylbenzenes in 4-MethylN-butylpyridinium Tetrafluoroborate Using Gas-Liquid Chromatography. J. Chem. Eng. Data 2001, 46, 1526-1529.

(7) Heintz, A.; Kulikov, D. V.; Verevkin, S. P. Thermodynamic Properties of Mixtures Containing Ionic Liquids. 2. Activity Coefficients at Infinite Dilution of Hydrocarbons and Polar Solutes in 1-Methyl-3ethyl-imidazolium Bis(trifluoromethyl-sulfonyl)amide and in 1,2Dimethyl-3-ethylimidazolium Bis(trifluoromethylsulfonyl)amide Using Gas-Liquid Chromatography. J. Chem. Eng. Data 2002, 47, 894899.

(8) Krummen, N.; Wasserscheid, P.; Gmehling, J. Measurement of Activity Coefficients at Infinite Dilution in Ionic Liquids Using the Dilutor Technique. J. Chem. Eng. Data 2002, 47, 1411-1417.

(9) Warren, D.; Letcher, T. M.; Ramjugernath, D.; Raal, J. D. Activity Coefficients of Hydrocarbon Solutes at Infinite Dilution in the Ionic Liquid, 1-Methyl-3-octylimidazolium Chloride from Gas-Liquid Chromatography. J. Chem. Thermodyn. 2003, 35, 1335-1341.

(10) Heintz, A.; Verevkin, S. P.; Ondo, D. Thermodynamic Properties of Mixtures Containing Ionic Liquids. 8. Activity Coefficients at Infinite Dilution Of Hydrocarbons, Alcohols, Esters, and Aldehydes in 1-Hexyl-3-methylimidazolium Bis(trifluoromethylsulfonyl)imide Using Gas-Liquid Chromatography. J. Chem. Eng. Data 2006, 51, 434-437. 
(11) Foco, G. M.; Bottini, S. B.; Quezada, N.; De la Fuente, J. C.; Peters, C. J. Activity Coefficients at Infinite Dilution in 1-Alkyl-3-methylimidazolium Tetrafluoroborate Ionic Liquids. J. Chem. Eng. Data 2006, 51, 1088-1091.

(12) Mutelet, F.; Butet, V.; Jaubert, J.-N. Application of Inverse Gas Chromatography and Regular Solution Theory for Characterization of Ionic Liquids. Ind. Eng. Chem. Res. 2005, 44, 4120-4127.

(13) Jacquemin, J.; Husson, P.; Majer, V.; Costa Gomes, M. F. LowPressure Solubilities and Thermodynamics of Solvation of Eight Gases in 1-Butyl-3-methylimidazolium Hexafluorophosphate. Fluid Phase Equilib. 2006, 240, 87-95.

(14) Anthony, J. L.; Maginn, E. J.; Brennecke, J. F. Solubilities and Thermodynamic Properties of Gases in the Ionic Liquid 1-N-Butyl3-methylimidazolium Hexafluorophosphate. J. Phys. Chem. B 2002, 106, 7315-7320

(15) Katritzky, A. R.; Mu, L.; Karelson, M. A QSPR Study of the Solubility of Gases and Vapors in Water. J. Chem. Inf. Comput. Sci. 1996, 36 , $1162-1168$.

(16) Katritzky, A. R.; Wang, Y.; Sild, S.; Tamm, T.; Karelson, M. QSPR Studies on Vapor Pressure, Aqueous Solubility, and the Prediction of Water-Air Partition Coefficients. J. Chem. Inf. Comput. Sci. 1998, 38, $720-725$.

(17) Katritzky, A. R.; Taemm, K.; Kuanar, M.; Fara, D. C.; Oliferenko, A.; Oliferenko, P.; Huddleston, J. G.; Rogers, R. D. Aqueous Biphasic Systems. Partitioning of Organic Molecules: A QSPR Treatment. J. Chem. Inf. Comput. Sci. 2004, 44, 136-142.

(18) Katritzky, A. R.; Kuanar, M.; Fara, D. C.; Karelson, M.; Acree, W. E. QSPR Treatment of Rat Blood:Air, Saline:Air and Olive Oil:Air Partition Coefficients Using Theoretical Molecular Descriptors. Bioorg. Med. Chem. 2004, 12, 4735-4748.

(19) Katritzky, A. R.; Kuanar, M.; Fara, D. C.; Karelson, M.; Acree, W. E.; Solov'ev, V. P.; Varnek, A. QSAR Modeling of Blood:Air and Tissue: Air Partition Coefficients Using Theoretical Descriptors. Bioorg. Med. Chem. 2005, 13, 6450-6463.

(20) Katritzky, A. R.; Dobchev, D. A.; Huer, E.; Fara, D. C.; Karelson, M. QSAR Treatment of Drugs Transfer into Human Breast Milk. Bioorg. Med. Chem. 2005, 13, 1623-1632.

(21) Katritzky, A. R.; Kuanar, M.; Slavov, S.; Dobchev, D. A.; Fara, D. C.; Karelson, M.; Acree, W. E.; Solov'ev, V. P.; Varnek, A. Correlation of Blood-Brain Penetration Using Structural Descriptors. Bioorg. Med. Chem. 2006, 14, 4888-4917.

(22) Katritzky, A. R.; Lomaka, A.; Petrukhin, R.; Jain, R.; Karelson, M.; Visser, A. E.; Rogers, R. D. QSPR Correlation of The Melting Point for Pyridinium Bromides, Potential Ionic Liquids. J. Chem. Inf. Comput. Sci. 2002, 42, 71-74.

(23) Katritzky, A. R.; Jain, R.; Lomaka, A.; Petrukhin, R.; Karelson, M.; Visser, A. E.; Rogers, R. D. Correlation of the Melting Points of Potential Ionic Liquids (Imidazolium Bromides and Benzimidazolium Bromides) Using the CODESSA Program. J. Chem. Inf. Comput. Sci. 2002, 42, 225-231.

(24) Trohalaki, S.; Pachter, R.; Drake, G. W.; Hawkins, T. Quantitative Structure-Property Relationships for Melting Points and Densities of Ionic Liquids. Energy Fuels 2005, 19, 279-284.

(25) Eike, D. M.; Brennecke, J. F.; Maginn, E. J. Predicting Melting Points of Quaternary Ammonium Ionic Liquids. Green Chem. 2003, 5, 323 328.

(26) Carrera, G.; Aires-de-Sousa, J. Estimation of Melting Points of Pyridinium Bromide Ionic Liquids with Decision Trees and Neural Networks. Green Chem. 2005, 7, 20-27.

(27) Varnek, A.; Kireeva, N.; Tetko, I. V.; Baskin, I. I.; Solov'ev, V. P. Exhaustive QSPR Studies of a Large Diverse Set of Ionic Liquids: How Accurately Can We Predict Melting Points. J. Chem. Inf. Model 2007, 47, 1111-1122.

(28) Lopez-Martin, I.; Burello, E.; Davey, P. N.; Seddon, K. R.; Rothenberg, G. Anion and Cation Effects on Imidazolium Salt Melting Points: a Descriptor Modelling Study. Chem. Phys. Chem. 2007, 8, 690-695.

(29) Abraham, M. H.; Zissimos, A. M.; Huddleston, J. G.; Willauer, H. D.; Rogers, R. D.; Acree, W. E., Jr. Some Novel Liquid Partitioning Systems: Water-Ionic Liquids and Aqueous Biphasic Systems. Ind. Eng. Chem. Res. 2003, 42, 413-418.

(30) Acree, W. E., Jr.; Abraham, M. H. The Analysis of Solvation in Ionic Liquids and Organic Solvents Using the Abraham Linear Free Energy Relationship. J. Chem. Technol. Biotechnol. 2006, 81, 1441-1446.

(31) Sprunger, L.; Clark, M.; Acree, W. E., Jr.; Abraham, M. H. Characterization of Room-Temperature Ionic Liquids by the Abraham Model with Cation-Specific and Anion-Specific Equation Coefficients. J. Chem. Inf. Model 2007, 47, 1123-1129.

(32) Gutowski, K. E.; Holbrey, J. D.; Rogers, R. D.; Dixon, D. A. Prediction of the Formation and Stabilities of Energetic Salts and Ionic Liquids Based on ab Initio Electronic Structure Calculations. J. Phys. Chem. B 2005, 109, 23196-23208.
(33) Diedenhofen, M.; Eckert, F.; Klamt, A. Prediction of Infinite Dilution Activity Coefficients of Organic Compounds in Ionic Liquids Using COSMO-RS. J. Chem. Eng. Data 2003, 48, 475-479.

(34) Kato, R.; Gmehling, J. Systems with Ionic Liquids: Measurement of VLE and $\Gamma \infty$ Data and Prediction of their Thermodynamic Behavior Using Original UNIFAC, mod. UNIFAC (Do) and COSMO-RS(OI). J. Chem. Thermodyn. 2005, 37, 603-619.

(35) Eike, D. M.; Brennecke, J. F.; Maginn, E. J. Predicting Infinite-Dilution Activity Coefficients of Organic Solutes in Ionic Liquids. Ind. Eng. Chem. Res. 2004, 43, 1039-1048.

(36) Tamm, K.; Burk, P. QSPR Analysis for Infinite Dilution Activity Coefficients of Organic Compounds. J. Mol. Model 2006, 12, 417421.

(37) Couling, D. J.; Bernot, R. J.; Docherty, K. M.; Dixon, J. K.; Maginn, E. J. Assessing the Factors Responsible for Ionic Liquid Toxicity to Aquatic Organisms Via Quantitative Structure-Activity Relationship Modeling. Green Chem. 2006, 8, 82-90.

(38) Katritzky, A. R.; Oliferenko, A. A.; Oliferenko, P. V.; Petrukhin, R.; Tatham, D. B.; Maran, U.; Lomaka, A.; Acree, W. E., Jr. A General Treatment of Solubility. 1. The QSPR Correlation of Solvation Free Energies of Single Solutes in Series of Solvents. J. Chem. Inf. Comput. Sci. 2003, 43, 1794-1805.

(39) Katritzky, A. R.; Oliferenko, A. A.; Oliferenko, P. V.; Petrukhin, R.; Tatham, D. B.; Maran, U.; Lomaka, A.; Acree, W. E., Jr. A General Treatment of Solubility. 2. QSPR Prediction of Free Energies of Solvation of Specified Solutes in Ranges of Solvents. J. Chem. Inf. Comput. Sci. 2003, 43, 1806-1814.

(40) Katritzky, A. R.; Tulp, I.; Fara, D. C.; Lauria, A; Maran, U.; Acree, W. E., Jr. A General Treatment of Solubility. 3. Principal Component Analysis (PCA) of the Solubilities of Diverse Solutes in Diverse Solvents. J. Chem. Inf. Model 2005, 45, 913-923.

(41) Heintz, A.; Vasiltsova, T. V.; Safarov, J.; Bich, E.; Verevkin, S. P. Thermodynamic Properties of Mixtures Containing Ionic Liquids. 9. Activity Coefficients at Infinite Dilution of Hydrocarbons, Alcohols, Esters, and Aldehydes in Trimethylbutylammonium Bis(trifluoromethylsulfonyl) Imide Using Gas-Liquid Chromatography and Static Method. J. Chem. Eng. Data 2006, 51, 648-655.

(42) Vasiltsova, T. V.; Verevkin, S. P.; Bich, E.; Heintz, A.; Bogel-Lukasil, R.; Domanska, U. Thermodynamic Properties of Mixtures Containing Ionic Liquids. Activity Coefficients of Ethers and Alcohols in 1-Methyl-3-ethylimidazolium Bis(trifluoromethylsulfonyl)imide Using the Transpiration Method. J. Chem. Eng. Data 2005, 50, 142-148.

(43) Vasiltsova, T. V.; Verevkin, S. P.; Bich, E.; Heintz, A.; Bogel-Lukasil, R.; Domanska, U. Thermodynamic Properties of Mixtures Containing Ionic Liquids. 7. Activity Coefficient of Aliphatic and Aromatic Esters and Benzylamine in 1-Methyl-3-ethylimidazolium Bis(trifluoromethyl)imide Using The Transpiration Method. J. Chem. Eng. Data 2006, $51,213-218$

(44) Deenadayalu, N.; Letcher, T. M.; Reddy, P. Determination of Activity Coefficients at Infinite Dilution of Polar and Nonpolar Solutes in the Ionic Liquid 1-Ethyl-3-methylimidazolium Bis(trifluoromethylsulfonyl)imide Using Gas-Liquid Chromatography at the Temperature 303.15 or 318.15 K. J. Chem. Eng. Data 2005, 50, 105-108.

(45) Camper, D.; Becker, C.; Koval, C.; Nobel, R. Low Pressure Hydrocarbon Solubility in Room Temperature Ionic Liquids Containing Imidazolium Rings Interpreted Using Regular Solution Theory. Ind. Eng. Chem. Res. 2005, 44, 1928-1933.

(46) Camper, D.; Becker, C.; Koval, C.; Nobel, R. Diffusion and Solubility Measurements in Room Temperature Ionic Liquids. Ind. Eng. Chem. Res. 2006, 45, 445-450.

(47) Letcher, T. M.; Marciniak, A.; Marciniak, M.; Domanska, U. Activity Coefficients at Infinite Dilution Measurements for Organic Solutes in the Ionic Liquid 1-Hexyl-3-methylimidazolium Bis(trifluoromethylsulfonyl)imide Using g.l.c. at $T=(298.15,313.15$, and 333.15) K. J. Chem. Thermodyn. 2005, 37, 1327-1331.

(48) Kumelan, J.; Perez-Salado Kamps, A.; Tuma, D.; Maurer, G. Solubility of $\mathrm{CO}_{2}$ in the Ionic Liquid [hmim] [Tf $\left.{ }_{2} \mathrm{~N}\right]$. J. Chem. Thermodyn. 2006, $51,1364-1367$.

(49) Shiflett, M. B.; Yokozeki, A. Solubility and Diffusivity of Hydrofluorocarbons in Room-Temperature Ionic Liquids. AIChE J. 2006, 52, $1205-1219$.

(50) Heintz, A.; Casas, L. M.; Nesterov, I. A.; Emel'yanenko, V. N.; Verevkin, S. P. Thermodynamic Properties of Mixtures Containing Ionic Liquids. 5. Activity Coefficients at Infinite Dilution of Hydrocarbons, Alcohols, Esters, and Aldehydes in 1-Methyl-3butylimidazolium Bis(trifluoromethylsulfonyl)imide Using GasLiquid Chromatography. J. Chem. Eng. Data 2005, 50, 1510-1514.

(51) Lee, B.-C.; Outcalt, S. L. Solubilities of Gases in the Ionic Liquid 1-N-Butyl-3-methylimidazolium Bis(trifluoromethylsulfonyl)imide. J. Chem. Eng. Data 2006, 51, 892-897. 
(52) Heintz, A.; Verevkin, S. P. Thermodynamic Properties of Mixtures Containing Ionic Liquids. 6. Activity Coefficients at Infinite Dilution of Hydrocarbons, Alcohols, Esters, and Aldehydes in 1-Methyl-3-octylimidazolium Tetrafluoroborate Using Gas-Liquid Chromatography. J. Chem. Eng. Data 2005, 50, 1515-1519.

(53) ChemDraw, v. 8.0; CambridgeSoft, 2003.

(54) Hyperchem, v. 7.01; Hypercube Inc.: Gainesville, FL, 2002.

(55) Codessa Pro, v. 1.0; University of Florida: Gainesville, FL, 2002.
(56) Katritzky, A. R.; Mu, L.; Lobanov, V. S.; Karelson, M. Correlation of Boiling Points with Molecular Structure. A Training Set of 298 Diverse Organics and a Test Set of 9 Simple Inorganics. J. Phys. Chem. 1996, 100, 10400-10407.

Received for review October 18, 2007. Accepted February 20, 2008.

JE700607B 